\title{
Self reported non-insulin dependent diabetes, family history, and risk of prevalent colorectal cancer: population based, cross sectional study
}

\author{
M S Sandhu, R Luben, K-T Khaw
}

Several studies have shown positive associations between non-insulin dependent diabetes (NIDDM) and incidence of colorectal cancer. ${ }^{1-3}$ This relation, as well as the marked similarity of dietary and lifestyle risk factors for the two conditions, has led investigators to propose that hyperinsulinaemia may be the underlying link between NIDDM and colorectal cancer. ${ }^{3}$ It is thought that raised insulin levels, either indirectly or directly, may promote the growth of colorectal tumours. ${ }^{13}$ Thus people with an inherited susceptibility to colorectal cancer and who also have NIDDM may be expected to be at even greater risk of colorectal cancer than from either risk factor alone. One measure of inherited susceptibility is family history of disease-an established risk factor for colorectal cancer. ${ }^{4}$ We therefore examined the relation between NIDDM, family history and risk of prevalent colorectal cancer among middle aged and older British adults using data from a large population based study.

\section{Participants, methods, and results}

Participants for this analysis were recruited between 1993 and 1997 as part of the East Anglian component of the European Prospective Investigation into Cancer (EPIC-Norfolk). The detailed design of the study has been previously described. ${ }^{6}$ Briefly, all men and women aged 45-74 years identified from lists of participating general practices were invited to join the study. The participants completed a detailed health and lifestyle questionnaire, which included questions on smoking (current, former, and never), height, weight, level of education (further education), past history of disease, age of diagnosis, and family history of disease. Prevalent colorectal cancer (International Classification of Diseases, ${ }^{7}$ ICD-9 153.0-153.9, 154.0 and 154) was ascertained by matching participants to the East Anglian Cancer Registry. For these analyses, we excluded all participants with prevalent cancer other than colorectal cancer or non-melanoma skin cancer, those with diabetes diagnosed before age 30 years as they were more likely to have insulin-dependent diabetes, and all diabetics who did not report their age of diagnosis. Unconditional multivariate logistic regression was used to measure the association between NIDDM, family history and risk of prevalent colorectal cancer. Maximum likelihood methods were used to estimate odds ratios and $95 \%$ confidence intervals.

Of the 29343 participants in this analysis, $561(1.9 \%)$ reported having NIDDM and $2005(6.8 \%)$ reported a family history of colorectal cancer in at least one first degree relative. Table 1 shows odds ratios for risk of prevalent colorectal associated with NIDDM and family history. We found that among participants who reported no family history of colorectal cancer and had NIDDM, the multivariate odds ratio was 2.53 (95\% CI 1.16, 5.55), and for those with a family history of colorectal cancer and who also had NIDDM the multivariate odds ratio was $4.80(95 \%$ CI $1.01,22.90)$.

\section{Comment}

We found a strong positive association between NIDDM and prevalent colorectal cancer. Our data also indicate that this association is modified by a family history of colorectal cancer,

\section{Department of Public Health and Primary Care, Institute of Public Health, University of \\ Cambridge School of Clinical Medicine, UK \\ Correspondence to: Dr Sandhu, Department of Public Health and Primary Care, Strangeways Research Laboratory, Wort's \\ Causeway, Cambridge CB1 8RN \\ (manj.sandhu@srl.cam.ac.uk)}

Accepted for publication 13 May 2001
Table 1 Self reported NIDDM, family history and risk of prevalent colorectal cancer among study participants

\begin{tabular}{|c|c|c|c|c|}
\hline Participants & $\begin{array}{l}\text { Prevalent cases (\% } \\
\text { with D) }\end{array}$ & $\begin{array}{l}\text { Controls (\% with } \\
\text { D) }\end{array}$ & $\begin{array}{l}\text { Age adjusted OR } R^{\star}(95 \% \\
\text { confidence limits) }\end{array}$ & $\begin{array}{l}\text { Multivariate OR }+(95 \% \\
\text { confidence limits) }\end{array}$ \\
\hline \multicolumn{5}{|l|}{ Men $\$$} \\
\hline No diabetes & 72 & 12775 & 1.0 & 1.0 \\
\hline Diabetes & $6(7.7)$ & $340(2.6)$ & $2.37(1.02,5.51)$ & $3.11(1.32,7.33)$ \\
\hline \multicolumn{5}{|l|}{ Women $\sqrt{ }$} \\
\hline No diabetes & 66 & 15869 & 1.0 & 1.0 \\
\hline Diabetes & $3(4.3)$ & $212(1.3)$ & $2.11(0.65,6.82)$ & $2.53(0.77,8.33)$ \\
\hline \multicolumn{5}{|l|}{ All $\ddagger \varnothing$} \\
\hline No diabetes & 138 & 28644 & 1.0 & 1.0 \\
\hline Diabetes & $9(6.1)$ & $552(1.9)$ & $2.27(1.14,4.49)$ & $2.91(1.45,5.83)$ \\
\hline \multicolumn{5}{|l|}{ All † } \\
\hline No family history & 126 & 27212 & 1.0 & 1.0 \\
\hline Family history & $21(14.3)$ & $1984(6.8)$ & $2.13(1.35,3.37)$ & $2.29(1.40,3.75)$ \\
\hline \multicolumn{5}{|c|}{ Participants with no family history of colorectal cancerł } \\
\hline No diabetes & 119 & 26692 & 1.0 & 1.0 \\
\hline Diabetes & $7(5.6)$ & $520(1.9)$ & $2.01(0.93,4.34)$ & $2.53(1.16,5.55)$ \\
\hline \multicolumn{5}{|c|}{ Participants with a family history of colorectal cancer $\ddagger$} \\
\hline No diabetes & 19 & 1952 & 1.0 & 1.0 \\
\hline Diabetes & $2(9.5)$ & $32(1.6)$ & $5.12(1.11,23.72)$ & $4.80(1.01,22.90)$ \\
\hline
\end{tabular}

Percentages may vary because of missing data values, $\mathrm{OR}=$ odds ratio. ${ }^{\star}$ Adjusted for age as a continuous variable. $†$ Adjusted for age as a continuous variable, smoking status (current, former and never), BMI (quintiles), further education (yes or no) and alcohol consumption (units per week). $\ddagger$ Adjusted for sex. \Adjusted for family history of colorectal cancer. ๆAdjusted for NIDDM. 
with an almost fivefold increased risk in participants with both a family history and NIDDM. This interdependency could be the result of various biological mechanisms. Inherited susceptibility to colorectal cancer-as defined by familial aggregation-is believed to be a composite of shared environmental factors and polygenic mechanisms, which include recognised familial syndromes, mismatch repair gene mutations and genetic polymorphisms involved in nutrient or carcinogenic metabolism. ${ }^{4}$ These processes may lead to an increase in the rate of tumour initiation and progression. ${ }^{4}$ In turn, this increased risk may be potentiated by NIDDM and its determinants. For example, hyperinsulinaemia, which is characteristic of early NIDDM, may promote colorectal carcinogenesis either directly, ${ }^{3}$ or indirectly through changes in the insulin-like growth factor system. ${ }^{8}$

Our results compare well with previous prospective assessments of the relation between NIDDM and colorectal cancer risk, ${ }^{12}$ and it is unlikely that confounding by other risk factors for colorectal cancer and correlates of family history or NIDDM may have explained our findings. ${ }^{25}$ In addition, as risk estimates for self reported NIDDM and family history in this study are similar to reports using medical records or validation studies to confirm self reported family history and NIDDM, ${ }^{145}$ ascertainment bias is unlikely to have explained our results. The association between NIDDM and colorectal cancer risk could have been the result of detection bias, although an earlier study found that the association was stronger for advanced and fatal colorectal cancer, ${ }^{1}$ which would have been less prone to detection and diagnostic biases. However, because of the small number of cases, the result for the combined effect may have arisen by chance as a consequence of sampling variation.

In summary, these findings provide further indirect epidemiological evidence for the hypothesis that hyperinsulinaemia may be important in the development of colorectal cancer. The possible influence of family history on NIDDM and risk of colorectal cancer merits further investigation.

We thank all participants and the general practitioners who have helped with this study, and to the nurses, technicians and the staff of the EPIC coordinating centre.

Funding: the cohort of the European Prospective Investigation of Cancer in Norfolk is supported by grant funding from the Cancer Research Campaign, the Medical Research Council, the Stroke Association, the British Heart Foundation, the Department of Health, the Europe Against Cancer Programme of the Commission of the European Communities and Ministry of Agriculture, Fisheries and Food. MSS is funded by the Medical Research Council.

Conflicts of interests: none.

$1 \mathrm{Hu}$ FB, Manson JE, Liu S, et al. Prospective study of adult onset diabetes mellitus and risk of colorectal cancer in women. F Natl Cancer Inst 1999;91:542-7

2 Will JC, Galuska DA, Vinicor F, et al. Colorectal cancer: another complication of diabetes mellitus? Am 7 Epidemiol.

3 Giovannucci E. Insulin and colon cancer. Cancer Causes Control. 1994;6:164-79

4 Houlston RS, Peto J. Genetics and the common cancers. In: Eeles RA, Ponder BAJ, Easton DF, eds. Genetic predisposiEeles RA, Ponder BAJ, Easton DF, eds. Genetic predisposi-
tion to cancer. London: Chapman and Hall, 1996:208-26.

5 Fuchs CS, Giovannucci EL, Colditz GA, et al. A prospective Fuchs CS, Giovannucci EL, Colditz GA, et al. A prospective
study of family history and the risk of colorectal cancer. $N$ study of family history and the
Engl FMed 1994;331:1669-74

6 Day NE, Oakes S, Luben R, et al. EPIC in Norfolk: study design and characteristics of the cohort. Br f Cancer 1999; 80 (suppl 1): $95-103$

7 World Health Organisation. Manual of the international statistical classification of diseases. Injuries and causes of death. 9th revision. WHO: Geneva, 1977

8 Kaaks R, Toniolo P, Akhmedkhanov A, et al. Serum C-peptide, IGF-I, IGFBPs, and colorectal cancer in women. $\mathcal{F}$ Natl Cancer Inst 2000;92:1592-600. 